\title{
Characteriation of the spatial interplays of microbiome and environmental geochemistry in acid mine drainage
}

\author{
HUI YANG ${ }^{1,2}$, LINGFEI LIU $^{1}$, HAIYAN CHEN ${ }^{1,2}$, YUAN \\ GUO $^{1}$, ZENGPING NING ${ }^{1}$, LIKAI HAO ${ }^{1,3}$ \\ ${ }^{1}$ State Key Laboratory of Environmental Geochemistry, \\ Institute of Geochemistry, Chinese Academy of Sciences, \\ Guiyang, China \\ ${ }^{2}$ University of Chinese Academy of Sciences, Beijing, China \\ haolikai@mail.gyig.ac.cn \\ ${ }^{3}$ CAS Center for Excellence in Quaternary Science and \\ Global Change, Xi'an, China
}

Acid Mine Drainage (AMD) is produced when sulfidebearing material exposed to oxygen and water, which will lead to serious environmental problems. The production of AMD is mainly attributed to ion sulfides, as well as other metal sulfide minerals. AMD has large production volume, long time release and complex composition; and is easily affected by environmental geochemical factors, such as $\mathrm{pH}$, temperature, electrical conductivity, oxidation-reduction potential, solubale ion composition and microorganism activity. All these factors will lead to the transformation of iron minerals. The change of its stability in the environment can significantly affect the migration and transformation of heavy mentals in the environment. Therefore it is crucial to identify the factors control the stability of AMD for better understading of the production of the AMD and subsequent remediation.

Thus, in order to explore and environmental geochemisty factors that affect heavy metal transformation and migration, and to determine the microbial metagenomic mechanism for long-term stability of AMD system, 205 samples that are from different seasons and different depth of the AMD in Guiyang. The results indicated that heavy metals, including iron, aluminum, magnesium and calcium migrated in vertical section due to the effects of microbial iron cycling couppled release and adsorption with the increase of depth. However the migration of vertical ferrous iron and ferric iron had no significant changes due to the diversity of iron minerals and their unique adsorbability. The dissolution of iron in solution is completely influenced by the micro-environment. Most importantly, the fundamental factors controlling the dissolution and precipitation of iron are $\mathrm{DO}, \mathrm{pH}$ and $\mathrm{Eh}$. In addition, more microscopic and metagenomic analysis are still on the way to better understand the interaction of microorganisms and environmental geochemistry. 